\title{
Expression of Nucleoside Transporters in the Mouse Testis and Ovary
}

\author{
Katsuhito Nagai and Hiroki Konishi
}

Laboratory of Clinical Pharmacy and Therapeutics, Faculty of Pharmacy, Osaka Ohtani University, 3-11-1 Nishikiori-kita, Tondabayashi 584-0066, Japan

\begin{abstract}
Nucleoside transporters play key roles in the physiology of nucleosides and nucleobases in mammals and also contribute to the pharmacological actions produced by their analogs. Several mammalian nucleoside transporters have been identified at the molecular level. The aim of this study was to examine the expression of the major nucleoside transporter isoforms in the mouse testis and ovary. Equilibrative Nucleoside Transporter 1 (ENT1) and ENT2 were expressed in the mouse testis and ovary, which was consistent with the general consideration that these transporters are ubiquitous in mouse tissues. The expression of Concentrative Nucleoside Transporter 2 (CNT2) and CNT3, but not CNT1 was detected in the mouse testis. These three CNT isoforms were also expressed in the ovary. Therefore, we concluded that the mouse testis and ovary simultaneously exhibit multiple transport processes for nucleosides and bases and also that these transporters are responsible for the homeostatic control of biological levels of nucleosides and bases in these tissues.
\end{abstract}

Keywords: Nucleoside Transporter, Nucleoside, Nucleobase, Testis, Ovary

\section{INTRODUCTION}

Nucleosides and nucleobases are important precursors for nucleotide synthesis (Kong et al., 2004). Individual nucleosides, such as adenosine and guanosine, also exert a number of specialized functions (Osti et al., 1997; Shryock and Belardinelli, 1997). The therapeutic uses of these compounds as antineoplastic agents in clinical cancer chemotherapy have greatly advanced, because the various structural analogs of nucleosides and bases are cytotoxic (Marce et al., 2006; Nagai et al., 2007a; Marechal et al., 2009). Nucleosides, bases and their analogs require specific transporters for permeation through cell membranes because of their relative high hydrophilicities (Kong et al., 2004).

Five major isoforms of the mammalian nucleoside transporter have been reported (Yao et al., 1997;
Kong et al., 2004; Nagai et al., 2007b). Two genetically distinct Equilibrative Nucleoside Transporters (ENT) were identified, termed ENT1 and ENT2. ENT1 is a 460 residue protein that is predicted to have 11 transmembrane segments, the sequence of approximately $50 \%$ of these being identical to that of ENT2. ENT1 was shown to be completely inhibited by $100 \mathrm{nM}$ Nitrobenzylmercaptopurine Riboside (NBMPR), whereas ENT2 was unaffected by exposure to NBMPR at a concentration lower than $1 \mu \mathrm{M}$. A broad range of natural nucleosides and bases was reported to be transported via ENT1 in a Na+-independent manner, as well as ENT2. In addition to ENTs, three $\mathrm{Na}+$-dependent Concentrative Nucleoside Transporters (CNT), CNT1, CNT2 and CNT3, were cloned. CNT1 and CNT2 preferentially transport pyrimidine nucleosides and purine nucleosides, respectively, whereas CNT3 transports both nucleosides. $\begin{aligned} \text { Corresponding Author: } & \text { Katsuhito Nagai, Laboratory of Clinical Pharmacy and Therapeutics, Faculty of Pharmacy, } \\ & \text { Osaka Ohtani University, 3-11-1 Nishikiori-kita, Tondabayashi 584-0066, Japan Tel: +81-721-24-9184 } \\ & \text { Fax: +81-721-24-9164 }\end{aligned}$ 
The testis and ovary are essential tissues that are responsible for reproduction. The expression profiles of the Nucleoside Transporter (NT) have so far been reported in various tissues and cells (Kong et al., 2004). Whether various NT isoforms are expressed in testicular tissue remains unclear; however, the expression of CNT1 was shown at the cellular level (Kato et al., 2005). Furthermore, the expression of NT has not yet been investigated in the ovary. In the present study, we examined the expression profiles of NT isoforms in the testis and ovary.

\section{MATERIALS AND METHODS}

\subsection{Chemicals}

The total RNAs of the spleen, testis and ovary were obtained from Ambion Inc., (Austin, TX, USA). All other reagents were of commercial or analytical grade and required no further purification.

\subsection{RT-PCR}

RT-PCR analysis was performed according to our previously reported method (Nagai et al., 2003). The brain, small intestine, liver, kidney, lung and skeletal muscle were dissected from ddY male mice aged 5 weeks (Japan SLC Inc., Hamamatsu, Japan). The total RNAs of these tissues were extracted with Sepasol RNA-I super (Nacalai Tesque Inc., Kyoto, Japan) and purified with a GenEluteTM Mammalian Total RNA kit (Sigma Chemical Co., St. Louis, MO, USA) according to the manufacturer's instructions. Each total RNA was reverse-transcribed into cDNA by means of Oligo-T priming and Moloney murine leukemia virus reverse transcriptase (Sigma Chemical Co.) and cDNA was then PCR-amplified at $94^{\circ} \mathrm{C}$ for $30 \mathrm{sec}$, at $55^{\circ} \mathrm{C}$ for $30 \mathrm{sec}$ and at $72^{\circ} \mathrm{C}$ for $60 \mathrm{sec}$ with exTaq DNA polymerase (Takara Bio Inc., Otsu,
Japan). PCR products were then separated by $1.0 \%$ agarose gel electrophoresis. The synthetic oligonucleotide primers (Takara Bio Inc.,) used to investigate the expression of NT isoforms are listed in Table 1. RT-PCR analysis was performed three times in order to confirm the reproducibility of the expression profiles of NT isoforms. The detectable PCR products of the NT isoforms were subcloned into the pGEM-T vector (Promega Co., Madison, WI, USA) and then sequenced.

\section{RESULTS AND DISCUSSION}

NT is essential for nucleosides, bases and its analogs to exert their physiological and pharmacological functions in mammals and obtaining information on the detailed expression profiles of NT is of practical importance. Therefore, we examined the expression of the major NT isoforms in the mouse testis and ovary.

The results of the present study revealed that ENT1 and ENT2 mRNAs were expressed in the mouse testis and ovary, as well as in tissues that had previously been shown to express ENTs (Fig. 1). Except for the ovary and testis, the expression profiles of CNTs were consistent with those reported previously (Lu et al., 2004). The expression of CNT1 was not observed in the testis; however, the mRNAs for other two CNT isoforms were detected (Fig. 2). Three CNT isoforms were expressed in the mouse ovary. A previous study demonstrated that CNT1 was expressed in rat primary-cultured Sertoli cells (Kato et al., 2005), a finding that was not consistent with our results. Although we cannot clearly explain the reason for this contradiction, it may have been due to differences in the experimental animals used in the respective studies (rat versus mouse).

Table 1. Forward and reverse oligonucleotide primer sequences used for RT-PCR screening of NT isoforms

\begin{tabular}{|c|c|c|c|}
\hline Isoform & Direction & Sequence & Product \\
\hline \multirow[t]{2}{*}{ ENT1 } & Forward & 5'-TGTCCCAGAATGTGTCCTCTCGG-3' & 687 bp \\
\hline & Reverse & 5'-TGGGTGGAGAGTTGGGGC-3' & \\
\hline \multirow[t]{2}{*}{ ENT2 } & Forward & 5'-TCTTTGCCCTGACAGCAGCG-3' & 700 bp \\
\hline & Reverse & 5'-CAATCCATGACGTTGAAGAGC-3' & \\
\hline \multirow[t]{2}{*}{ CNT1 } & Forward & 5'-GCTGAAGAGAGGTCTAGCCC-3' & $821 \mathrm{bp}$ \\
\hline & Reverse & 5'-CGACCTTCACTGAGATGGCA-3' & \\
\hline \multirow[t]{2}{*}{ CNT2 } & Forward & 5'-TTTGGTGATACACTGGTCC-3' & $957 \mathrm{bp}$ \\
\hline & Reverse & 5'-CCTGACCACAATCTTGCAC-3' & \\
\hline \multirow[t]{2}{*}{ CNT3 } & Forward & 5'-TCTTTGGGGAAAAGTATACAG-3' & 959 bp \\
\hline & Reverse & 5'-TCTCATGGCTCCAGAGGCG-3' & \\
\hline
\end{tabular}


Katsuhito Nagai and Hiroki Konishi / American Journal of Biochemistry and Biotechnology 9 (4): 448-452, 2013

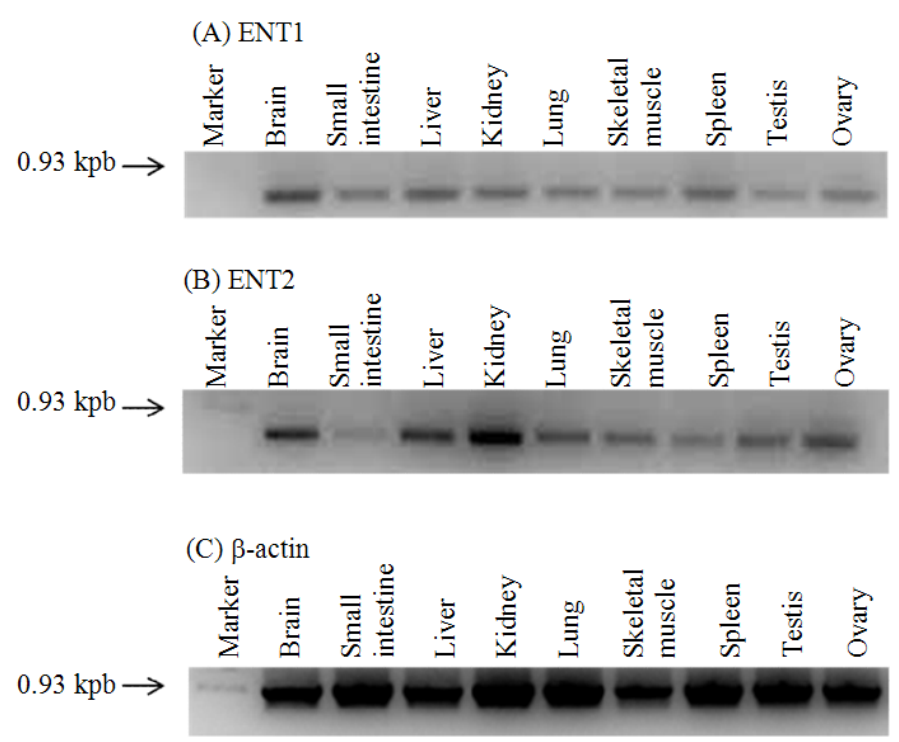

Fig. 1. Expression of ENTs in mouse tissues cDNA was PCR-amplified at $94^{\circ} \mathrm{C}$ for $30 \mathrm{sec}$, at $55^{\circ} \mathrm{C}$ for $30 \mathrm{sec}$ and at $72^{\circ} \mathrm{C}$ for $1 \mathrm{~min}$. PCR products were separated by electrophoresis with a $1.0 \%$ agarose gel. The sizes of the PCR products for ENT1 and ENT2 were $687 \mathrm{~kb}$ and $700 \mathrm{~kb}$, respectively

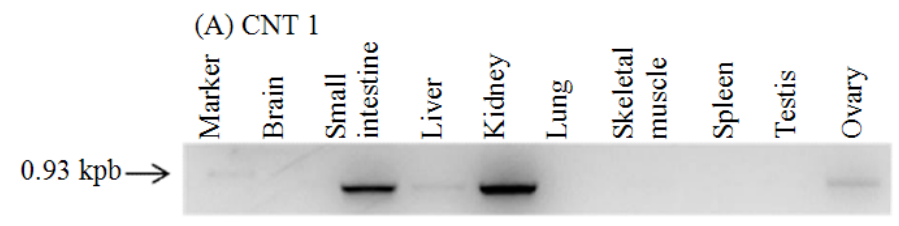

(B) CNT 2

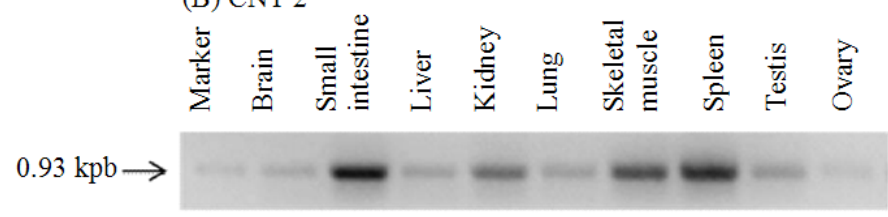

(C) CNT 3

离

$0.93 \mathrm{kpb} \rightarrow$

(D) $\beta$-actin

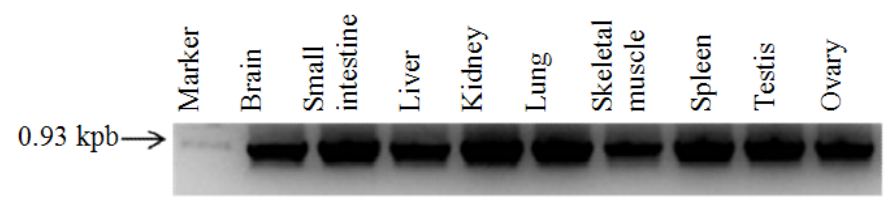

Fig. 2. Expression of CNTs in mouse tissues cDNA was PCR-amplified at $94^{\circ} \mathrm{C}$ for $30 \mathrm{sec}$, at $55^{\circ} \mathrm{C}$ for $30 \mathrm{sec}$ and at $72^{\circ} \mathrm{C}$ for $1 \mathrm{~min}$. PCR products were separated by electrophoresis with a $1.0 \%$ agarose gel. The sizes of the PCR products for CNT1, CNT2 and CNT3 were $821 \mathrm{~kb}, 957 \mathrm{~kb}$ and $959 \mathrm{~kb}$, respectively 
Both the testis and ovary are important endocrine glands necessary for reproduction. The proliferation, differentiation and survival of spermatogenic cells in the mammalian spermatogenic pathway were observed by interacting with Sertoli cells (Russel et al., 1990; Lui et al., 2003). Ovarian folliculogenesis is a complex process, during which follicles undergo tremendous growth and maturation. Beginning as a single layer of pregranulosa cells surrounding the immature oocyte, granulosa cells actively proliferate and differentiate until the time of ovulation (Maruo, 1995). The testis and ovary possess rate-limiting enzymes involved in the purine and pyrimidine salvage pathways, such as hypoxanthineguanine phosphoribosyltransferase, adenine phosphoribosyltransferase and uridine kinase, in order to biosynthesize DNA and RNA for proliferation and differentiation (Adair et al., 1983; Haugen et al., 1988; Steams et al., 2002). Therefore, these transporters may be responsible for the uptake of nucleosides and bases by spermatogenic cells and ovarian granulosa cells. Furthermore, CNT3 appeared to have been more abundantly expressed in the ovary than in the other tissues. This result suggests that CNT3 makes a significant contribution to the homeostatic maintenance of the biological levels of nucleosides in ovarian cells.

The transporting capacity of NT was previously reported to be a factor determining the cytotoxic behavior of anti-tumor nucleoside and base analogs (Marce et al., 2006; Nagai et al., 2007a; Marechal et al., 2009). Various NT isoforms were found to be expressed in the testis and ovary in the present study. This result strongly suggests that the onset of cytotoxicity also need to be considered in reproductive organs during chemotherapy.

\section{CONCLUSION}

In the present study, we demonstrated that two ENT isoforms, CNT2 and CNT3, but not CNT1 were expressed in the mouse testis and the expression of all NT isoforms examined was confirmed in the mouse ovary. Such information will enhance understanding of the more detailed physiological and pharmacological roles of NT.

\section{REFERENCES}

Adair, G.M., R.L. Stallings, R.S. Nairn and M.J. Siciliano, 1983. High-frequency structural gene deletion as the basis for functional hemizygosity of the adenine phosphoribosyltransferase locus in Chinese hamster ovary cell. Proc. Natl. Acad. Sci. USA., 80: 5961-5964. PMID: 6310607
Haugen, T.B., V. Hansson and P. Fritzson, 1988. Cellular distribution, developmental changes and effects of cryptorchidism on uridine kinase in the rat testis. J. Reprod. Fertil., 83: 655-661. PMID: 2900895

Kato, R., T. Maeda, T. Akaike and I. Tamai, 2005. Nucleoside transport at the blood-testis barrier studied with primary-cultured sertoli cells. J. Pharmacol. Exp. Ther., 312: 601-608. DOI: 10.1124/jpet.104.073387

Kong, W., K. Engel and J. Wang, 2004. Mammalian nucleoside transporters. Curr. Drug Metab., 5: 6384. DOI: $10.2174 / 1389200043489162$

Lu, H., C. Chen and C. Klaassen, 2004. Tissue distribution of concentrative and equilibrative nucleoside transporters in male and female rats and mice. Drug Metab. Dispos., 32: 1455-1461. DOI: 10.1124/dmd.104.001123

Lui, W.Y., D. Mruk, W.M. Lee and C.Y. Cheng, 2003. Sertoli cell tight junction dynamics: Their regulation during spermatogenesis. Biol. Reprod., 68: 1087-1097. DOI: 10.1095/biolreprod.102.010371

Marce, S., M. Molina-Arcas, N. Villamor, F.J. Casado and E. Campo et al., 2006. Expression of human equilibrative nucleoside transporter 1 (hENT1) and its correlation with gemcitabine uptake and cytotoxicity in mantle cell lymphoma. Haematologica, 91: 895-902. PMID: 16818276

Marechal, R., J.R. Mackey, R. Lai, P. Demetter and M. Peeters et al., 2009. Human equilibrative nucleoside transporter 1 and human concentrative nucleoside transporter 3 predict survival after adjuvant gemcitabine therapy in resected pancreatic adenocarcinoma. Clin. Cancer Res., 15: 2913-2919. DOI: 10.1158/1078-0432.CCR08-2080

Maruo, T., 1995. Expression of oncogenes, growth factors and their receptors in follicular growth, regression and atresia: Their roles in granulosa cell proliferation and differentiation. Nihon Sanka Fujinka Gakkai Zasshi, 47: 738-750. PMID: 7594883

Nagai, K., K. Nagasawa, A. Ishimoto and S. Fujimoto, 2003. Pirarubicin is taken up by a uridinetransportable sodium-dependent concentrative nucleoside transporter in Ehrlich ascites carcinoma cells. Cancer Chemother. Pharmacol., 51: 512-518. DOI: $10.1007 / \mathrm{S} 00280-003-0569-0$ 
Nagai, K., K. Nagasawa, Y. Kihara, H. Okuda and S. Fujimoto, 2007a. Anticancer nucleobase analogues 6-mercaptopurine and 6-thioguanine are novel substrates for equilibrative nucleoside transporter 2. Int. J. Pharm., 333: 56-61. DOI: 10.1016/j.ijpharm.2006.09.044

Nagai, K., K. Nagasawa, Y. Kyotani, N. Hifumi and S. Fujimoto, 2007b. Mouse equilibrative nucleoside transporter 2 (mENT2) transports nucleosides and purine nucleobases differing from human and rat ENT2. Biol. Pharm. Bull., 30: 979-981. PMID: 17473446

Osti, F., F.G. Corradini, S. Hanau, M. Matteuzzi and R. Gambari, 1997. Human leukemia K562 cells: induction to erythroid differentiation by guanine, guanosine and guanine nucleotides. Haematologica, 82: 395-401. PMID: 9299849

Russel, L.D., R.A. Ettlin, A.P. Hikim and E.D. Clegg, 1990. The Sertoli Cells. In: Histological and Histopathological Evaluation of the Testis, Russell, L.D. (Ed.), Cache River Press, Clearwater, ISBN10: 0962742201, pp: 29-36.
Shryock, J.C. and L. Belardinelli, 1997. Adenosine and adenosine receptors in the cardiovascular system: Biochemistry, physiology and pharmacology. Am. J. Cardiol., 79: 2-10. PMID: 9223356

Steams, D.M., S.M. Silveira, K.K. Wolf and A.M. Luke, 2002. Chromium(III) tris(picolinate) is mutagenic at the hypoxanthine (guanine) phosphoribosyltransferase locus in Chinese hamster ovary cells. Mutat. Res., 513: 135-142. PMID: 11719098

Yao, S.Y., A.M. Ng, W.R. Muzyka, M. Griffiths and C.E. Cass et al., 1997. Molecular cloning and functional characterization of nitrobenzylthioinosine (NBMPR)-sensitive (es) and NBMPR-insensitive (ei) equilibrative nucleoside transporter proteins (rENT1 and rENT2) from rat tissues. J. Biol. Chem., 272: 28423-28430. DOI: 10.1074/jbc.272.45.28423 